\title{
Metallothioneins in Failure of Dental Implants and Periodontitis Down Syndrome Patients
}

\author{
Maria Baus-Domínguez ${ }^{1}$, Raquel Gómez-Díaz ${ }^{2}$, Jose-Ramón Corcuera-Flores ${ }^{3}$, \\ Daniel Torres-Lagares ${ }^{1, * \mathbb{D}}$, José-Cruz Ruiz-Villandiego ${ }^{4}$, Guillermo Machuca-Portillo ${ }^{3}$, \\ José-Luis Gutiérrez-Pérez ${ }^{1,5, *}$ and María-Angeles Serrera-Figallo ${ }^{3}$ \\ 1 Oral Surgery Department, Dentistry Faculty, University of Seville, 41009 Seville, Spain; mbaus95@gmail.com \\ Instituto de Biomedicina de Sevilla, 41007 Seville, Spain; rgomez-ibi@us.es \\ Dentistry in Handicapped Patients Department, Dentistry Faculty, University of Seville, 41009 Seville, Spain; \\ joserra_64@hotmail.com (J.-R.C.-F.); gmachuca@us.es (G.M.-P.); maserrera@us.es (M.-A.S.-F.) \\ 4 Dentistry in Handicapped Patients Department, Quirón Hospital, 20012 San Sebastián, Spain; \\ maserrera@ono.com \\ 5 Oral and Maxillofacial Unit, Virgen del Rocio Hospital, 41009 Seville, Spain \\ * Correspondence: danieltl@us.es (D.T.-L.); jlgp@us.es (J.-L.G.-P.)
}

Received: 4 August 2019; Accepted: 12 September 2019; Published: 14 September 2019

\begin{abstract}
Background: Sometimes dental implants seem to be the only therapeutic alternative for the oral rehabilitation of patients with Down syndrome, given that they usually lose all their teeth early due to suffering aggressive periodontitis and they do not usually have the skills required to wear removable prostheses. However, the evolution of dental implants in these patients shows very adverse results. It is possible that basal genetic alterations, or at least some characteristics of these, may underlie these clinical results. The metabolic pathway of metallothioneins, molecules with an important influence on bone metabolism, could be one of the said alterations. Aims: To determine whether the expression of metallothioneins (MTs) and their metabolic pathway may be identified and related to the periodontitis and lack of osseointegration of dental implants in Down syndrome patients. Materials and Methods: Retrospective study of cases and controls by comparing patients with Down syndrome, periodontal disease, and implant failure (four patients, test group) with patients with Down syndrome, without periodontal disease, and without implant failure after two years of following (seven patients, control group), by extracting peripheral blood at the time of the dental examination to extract RNA and its subsequent processing in relation to gene expression of the metabolic pathway of metallothioneins. Results: The results identified low expression in the group of patients with periodontal disease and implant failure of genes MT1E, MT1H, MT1X, MT1A, MT1B, MT1C, MT1L, MT2A, MT1M, and MT1G. Conclusions: The low MT1 and MT2 gene expression seems to be related to the onset of periodontal disease and implant rejection in Down syndrome patients, although more data are required to confirm whether this relationship is due to one of the two conditions, to both independently, or to the two jointly-this last option being indicated by our current study.
\end{abstract}

Keywords: bone biology; clinical outcomes; gene expression; systemic health; systemic disease; osseointegration; periodontal disease; Down syndrome

\section{Introduction}

Down syndrome (DS) covers a large number of pathologies that affect practically every system in the body, including the cardiovascular, hematological, skeletal muscle, nervous, endocrine, and digestive systems. It affects patients' oral health to a large extent and, accordingly, determines their dental treatment. 
Despite the enormous number of orofacial and dental manifestations that can be found in Down syndrome patients, the main problem that this study concentrates on arises when these patients need dental replacements or complete rehabilitation due to the loss of their teeth, or when these have never existed (dental agenesis).

Given the intellectual disability of these patients, removable prostheses are often not advisable due to the difficulty in handling them, putting them in, or looking after them [1]. Fixed dental prostheses may be a better therapeutic option for the treatment of these patients, especially those with moderate or profound intellectual disability, since they tend to be well tolerated [2], although it is important to highlight that they must be well maintained (cleaned). For this reason, treatment with implants is sometimes the only option for supporting fixed dental prostheses in this type of patient [3,4].

In this context, there are a few case studies and controls, such as the one by Corcuera-Flores et al. [5], which show how the placing of implants in these patients may have adverse results. A large number of DS patients have lost teeth through aggressive periodontitis; could it be possible that some similar destructive process of the peri-implant support is taking place? Certain syndromes related to implant failure or with specific microbiological characteristics have been described [6-9].

In this connection, it would be interesting to know whether the metabolic pathway of metallothioneins is altered and could be the cause of the failure of implant treatment and/or periodontal disease in Down syndrome patients, which could be explained by an implication of these in the osseointegration process and/or in the aggressive periodontitis that DS patients present.

Metallothioneins (MTs) are a family of small metal proteins rich in cysteine, extremely different, generally of low molecular weight, which are capable of bonding to heavy metals both physiological ( $\mathrm{Zn}$ and $\mathrm{Cu}$ ) and xenobiotic ( $\mathrm{Cd}, \mathrm{Hg}$, and $\mathrm{Ag}$ ), via the thiol groups (-SH) of their cysteine residues. They are involved in the homeostasis and transport of essential metals-more specifically, in the protection of cells against the toxicity of heavy metals $[10,11]$. In humans, four genes that codify these molecules grouped in tandem (MT1 to MT4) are known. These genes are oriented cent-MT4-MT3-MT2-MT1-tel and flanked by BBS2 and NUP93 on chromosome 16. Furthermore, MT1 presents 13 grouped duplicates, isoforms (MT1A to MT1J, MT1L, MT1M, and MT1X), five of which (MT1L, MT1J, MT1D, MT1C, and MT1L) are predicted not to be active forms, and pseudogenes [12]. Currently it is thought that pseudogenes can act as possible regulators of the genes they come from and are not junk DNA, as had been thought up to now.

In tissues with a high rate of cell proliferation, a high rate of metallothionein synthesis has been detected. When these bind to zinc or copper, they act as a reservoir for the synthesis of apoenzymes. In zinc it is an important cofactor and, therefore, essential for cell growth. It has catalytic functions; more than 3000 proteins contain it in their structures; it modulates cell signaling, and kinase and phosphatase protein activities, as well as transcription factors; it also modulates GMPc metabolism, kinase C and MAPK activities, and MTF-1 activity, among many others [12,13].

The study is based on this question, with the following null hypothesis: the metabolic pathway of metallothioneins is expressed in the same way in the following groups of patients:

- Down syndrome patients who have suffered aggressive periodontitis and for whom implant treatment has failed.

- Down syndrome patients who have not suffered aggressive periodontitis and have a positive experience of implant treatment (more than two years' follow-up without bone loss problems (grade 1 on the Lavergall and Jansson scale) [14].

The alternative hypothesis is that the metabolic pathway of metallothioneins is expressed inconsistently, either upregulated or downregulated, among the two groups of patients studied. 


\section{Experimental Section}

\subsection{Type of Study}

Retrospective case study and controls approved by the corresponding Ethics Committee (Hospital Virgen del Rocío Ethical Committee-Case file PI-0081-2016). The study is descriptive and observational, where the only invasive procedure performed on patients is the collection of a small amount of blood and a dental examination. The patient (or the person responsible for them) gives their consent based on the direct benefits to the research patient.

\subsection{Selection of Patients and Study Groups}

The study groups were:

(1) Down syndrome patients without periodontal disease and successful implants after two years (-PD-FI), (2) Down syndrome patients with periodontal disease and failed implants after two years $(+\mathrm{PD}+\mathrm{FI})$.

A failed implant is understood as lost after two years' follow-up, or peri-implant bone loss of at least grade 2 on the Lagervall and Jansson scale [14].

It was intended to include 10 patients in each of these groups, for a total of 20 patients studied. In actual practice, the number of subjects in the study was reduced, with a total of seven patients for group 1 and four patients for group 2 .

The exclusion criteria were as follows:

- Non-Down syndrome patients

- Patients receiving treatment that could possibly affect bone metabolism, such as long-term corticosteroids, bisphosphonates, or monoclonal antibodies.

- Patients treated with short implants, or with immediate loading implants.

- Patients with active or untreated periodontal disease.

- Patients with implants inserted less than two years ago.

Once the patients had been identified, and the existence or not of periodontal disease and its grade had been confirmed from the medical records, patients were included in one of the two approaches (with periodontal disease and negative evolution implants; without periodontal disease and positive evolution implants).

In patients with implants inserted, panoramic X-rays were taken for all patients who still had implants to calculate the marginal bone loss (MBL). The panoramic X-rays were assessed to calculate the MBL of the bone loss using the Lagervall and Jansson index [14] and validated for its use in this type of study by Corcuera-Flores et al. [15]. This method divides the implants into four groups according to their MBL:

- Grade 0: implants with no marginal bone loss.

- Grade 1: marginal bone loss of one-third or less of the total length of the implant.

- Grade 2: one-third, but less than two-thirds, of the total length of the implant.

- Grade 3: marginal bone loss greater than two-thirds of the total length of the implant.

- A fifth group (Grade 4) was added of those patients where the implant was lost.

The panoramic $X$-rays taken at the time of inserting the implant were reviewed to check if any bone defect around it had occurred in the postoperative period, and that no defect was caused during its insertion. Subsequently, X-rays were taken after two years' evolution (or at the nearest possible time point, but always greater than two years). 


\subsection{Sampling and Total RNA Isolation}

At the time of examining the patients selected and included, sampling was undertaken, which comprised two collections of blood per patient collected in PAXgene tubes, reference 762165 (100 tubes), with the ultimate aim of RNA collection.

The transfer of samples to the processing center is under refrigeration $\left(2-8^{\circ} \mathrm{C}\right)$ for up to five days. For longer storage periods, the tubes are kept at $-20{ }^{\circ} \mathrm{C}$ or $-80^{\circ} \mathrm{C}$.

RNA sample collection was made using Qiagen's PAXgene Blood (QIAGEN GmbH, Hilden, Germany) miRNA Kit (50 tubes) reference 763134. The collection was carried out at the Qiagen QIAcube (QIAGEN GmbH, Hilden, Germany) automated station.

Subsequently, a database of the samples was compiled wherein we specified, among other information, data relating to DNA and RNA quantification.

\subsection{Gene Expression}

Firstly, RNA concentrations were quantified using a Thermo Scientific ${ }^{\mathrm{TM}}$ NanoDrop 2000c visible light spectrophotometer (Santa Clara, CA, USA), in order to ensure correct processing of these before their conservation.

Secondly, a much more precise measurement was taken, using Thermo Scientific's Qubit 3.0 fluorometer kit; in this case, only the samples selected for the first study of gene expression were added to the database.

The last step was a gene expression study to determine whether metallothioneins have differences in their expression in the different study groups.

The platform chosen for this study was Thermo Scientific's GeneChip ${ }^{\circledR}$ Scanner 3000, and the chips chosen were Clariom $S$ solutions for humans, mice, and rats, with more than 20,000 genes entered for measuring expression levels.

The RNA chosen was amplified and hybridized using Thermo Scientific's GeneChip ${ }^{\circledR}$ WT PLUS Reagent Kit.

Amplification was performed from an initial total of 55 grams and was undertaken in accordance with the manuals described in the GeneChip ${ }^{\circledR}$ WT PLUS Reagent Kit. Scanning with Thermo Scientific's GeneChip ${ }^{\circledR}$ Scanner 3000 was performed following the protocols for loading of the array cartridges (Figures 1 and 2).

Finally, analysis was performed normalizing and using the robust multi-array (RMA) method, and the analysis of the different gene expression was undertaken using transcriptome analysis console (TAC, Affymetrix) software. 


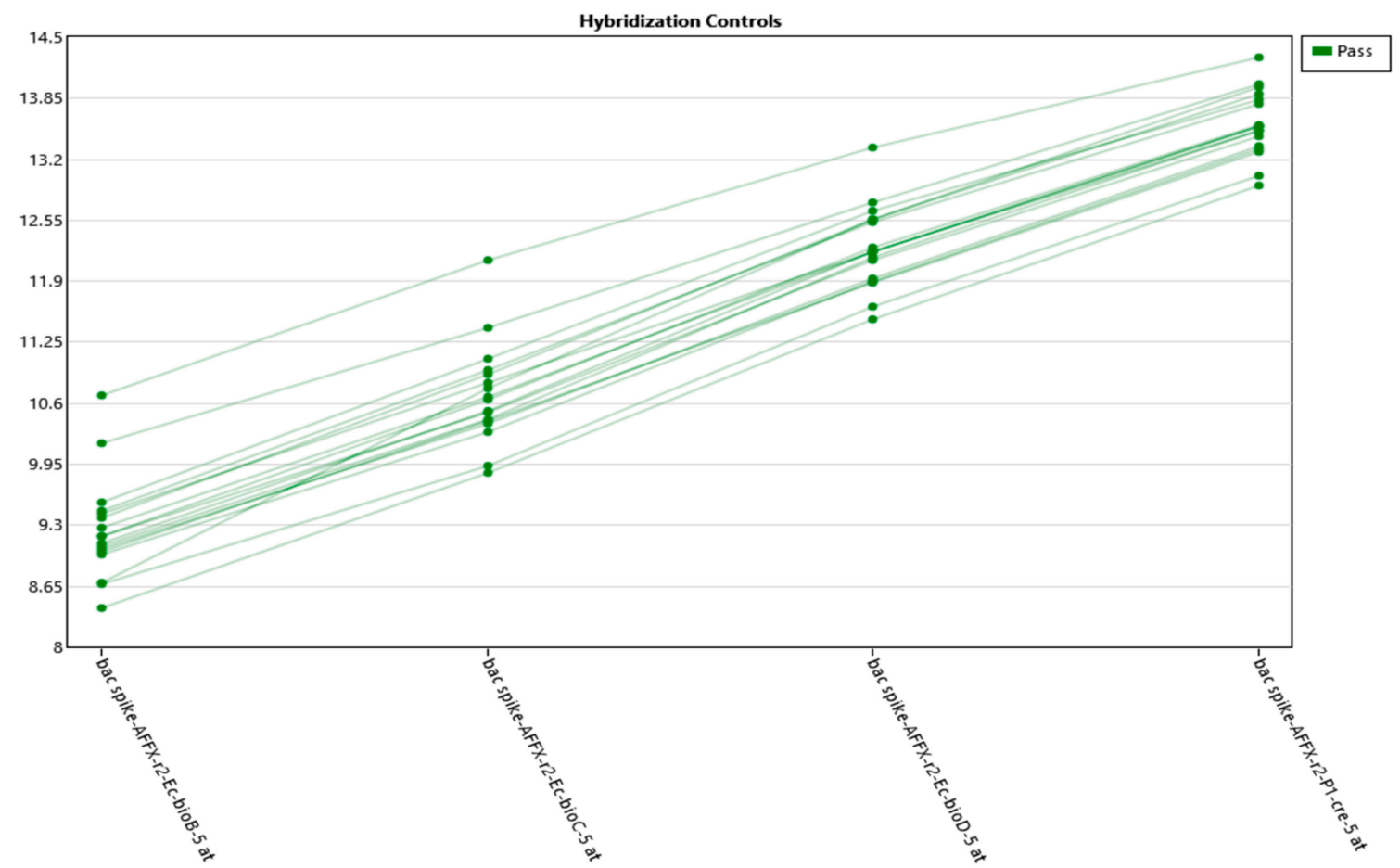

(a)

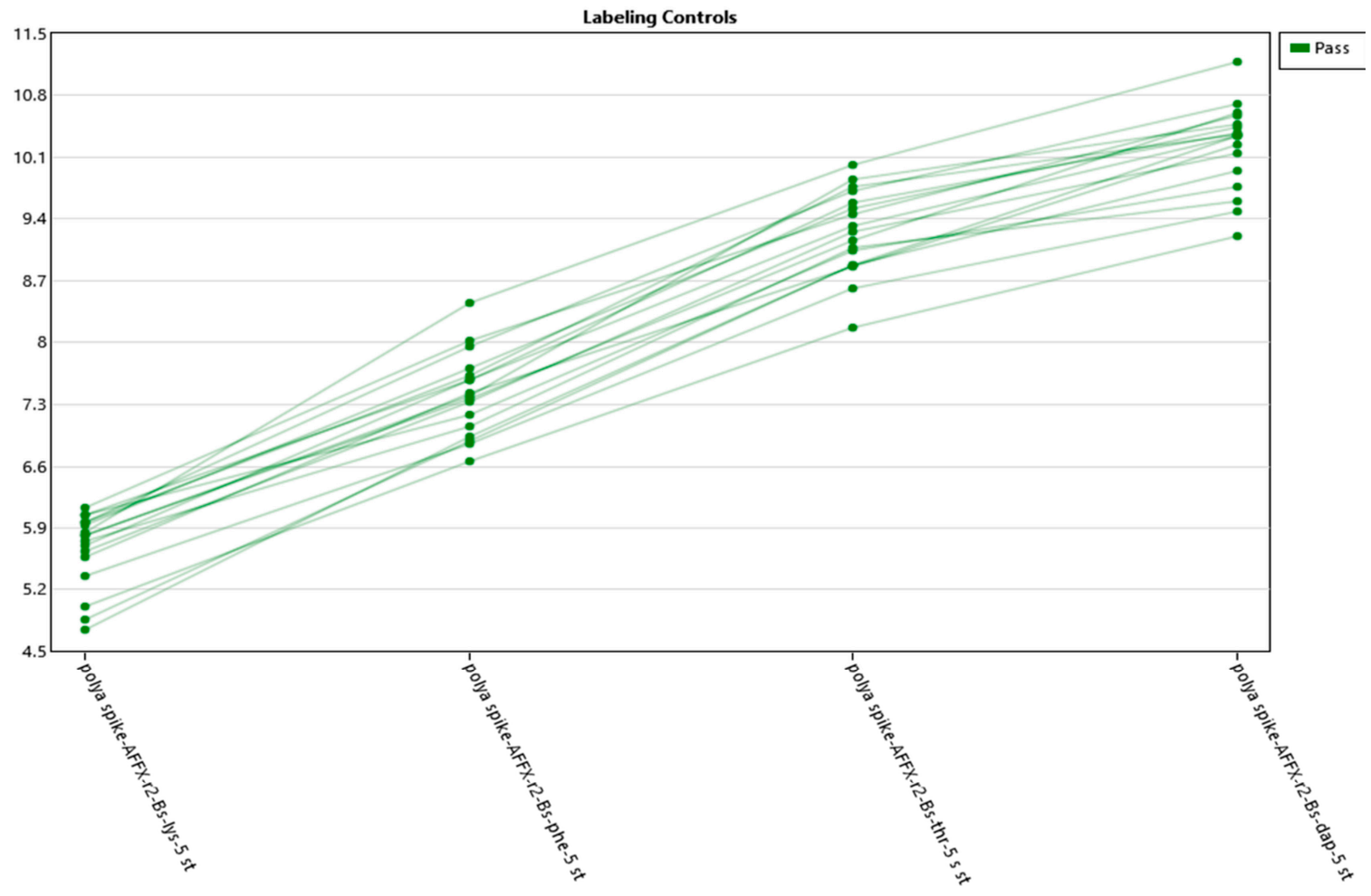

(b)

Figure 1. (a) Hybridization controls. Graphs on the quality controls provided by the platform, indicating that the experiment has been conducted correctly. (b) Labeling controls. Graphs on the quality controls provided by the platform, indicating that the experiment has been conducted correctly. 


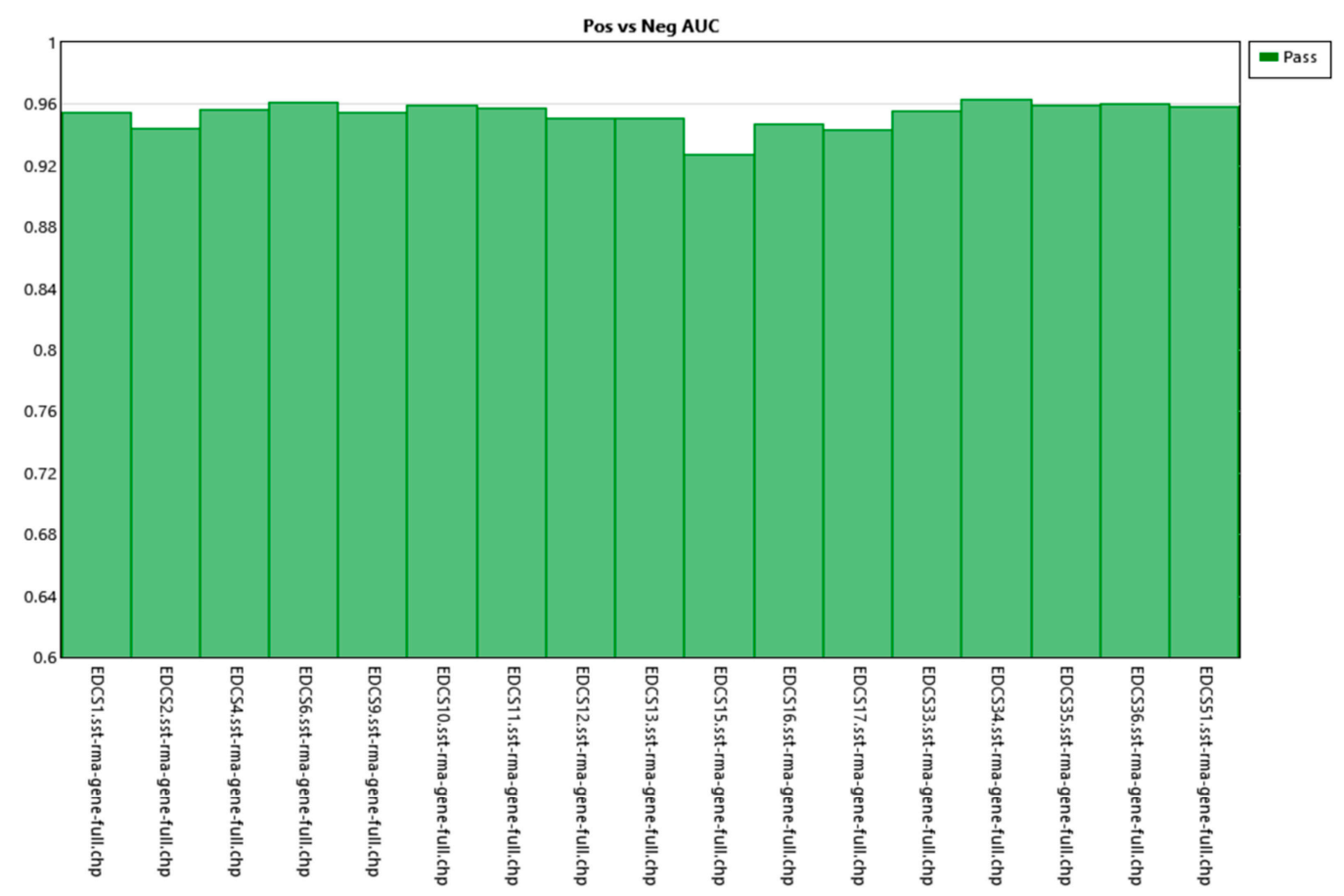

Figure 2. Positive vs. negative AUC. Shows the value of the samples analyzed. It can be seen that all are close to a value of 1 , which shows that the samples behave correctly and homogeneously.

\section{Results}

\subsection{Participants}

The patients included in the study are classified into different groups according to their diagnosis of periodontal disease and the evolution of their implants over two years.

A total of four patients with Down syndrome with periodontal disease and failed implants $(+\mathrm{PD}+\mathrm{FI})$ were compared with seven Down syndrome patients without periodontal disease and without failed implants (positive evolution of implants) (-PD-FI) (Table 1, Figures 3 and 4).

Table 1. Clinical data of the patients studied. Patients 9-11 did not have implants; it was assumed, from our clinical experience, that in the absence of periodontal disease, they would not be candidates for early failure after implant placement, in order to increase the number of patients in the control group. In any case, the results of the analysis, eliminating these patients, were similar.

\begin{tabular}{|c|c|c|c|c|c|c|c|c|c|}
\hline Patient & Group & Age & Sex & Smoker & Drinker & $\begin{array}{c}\text { History of } \\
\text { Controlled } \\
\text { Periodontal Disease }\end{array}$ & $\begin{array}{l}\text { Implants } \\
\text { Placed }\end{array}$ & $\begin{array}{c}\text { Bone } \\
\text { Regeneration }\end{array}$ & $\begin{array}{l}\text { Result after Two } \\
\text { Years of Follow-up }\end{array}$ \\
\hline 1 & $+\mathrm{PD}+\mathrm{FI}$ & 41 & Female & No & No & Yes & 2 implants & No & $\begin{array}{l}1 \text { implant lost and } 1 \\
\text { implants with severe } \\
\text { peri-implantitis }\end{array}$ \\
\hline 2 & $+\mathrm{PD}+\mathrm{FI}$ & 39 & Female & No & No & Yes & 3 implants & No & $\begin{array}{l}1 \text { implant lost and } 2 \\
\text { implants with severe } \\
\text { peri-implantitis }\end{array}$ \\
\hline 3 & $+\mathrm{PD}+\mathrm{FI}$ & 33 & Male & No & No & Yes & 4 implants & No & 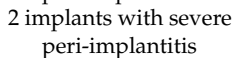 \\
\hline 4 & $+\mathrm{PD}+\mathrm{FI}$ & 35 & Male & No & No & Yes & 12 implants & No & 3 implants lost \\
\hline 5 & -PD-FI & 40 & Female & No & No & No & 3 implants & No & $\begin{array}{l}\text { No implant failure or } \\
\text { peri-implantitis }\end{array}$ \\
\hline 6 & -PD-FI & 34 & Female & No & No & No & 2 implants & No & $\begin{array}{l}\text { No implant failure or } \\
\text { peri-implantitis }\end{array}$ \\
\hline 7 & -PD-FI & 43 & Female & No & No & No & 3 implants & No & $\begin{array}{l}\text { No implant failure or } \\
\text { peri-implantitis }\end{array}$ \\
\hline 8 & -PD-FI & 48 & Female & No & No & No & 2 implants & No & $\begin{array}{l}\text { No implant failure or } \\
\text { peri-implantitis }\end{array}$ \\
\hline
\end{tabular}


Table 1. Cont.

\begin{tabular}{|c|c|c|c|c|c|c|c|c|c|}
\hline Patient & Group & Age & Sex & Smoker & Drinker & $\begin{array}{c}\text { History of } \\
\text { Controlled } \\
\text { Periodontal Disease }\end{array}$ & $\begin{array}{l}\text { Implants } \\
\text { Placed }\end{array}$ & $\begin{array}{c}\text { Bone } \\
\text { Regeneration }\end{array}$ & $\begin{array}{l}\text { Result after Two } \\
\text { Years of Follow-up }\end{array}$ \\
\hline 9 & -PD-FI & 44 & Male & No & No & No & No & No & $\begin{array}{l}\text { No implant failure or } \\
\text { peri-implantitis }\end{array}$ \\
\hline 10 & -PD-FI & 38 & Male & No & No & No & No & No & $\begin{array}{l}\text { No implant failure or } \\
\text { peri-implantitis }\end{array}$ \\
\hline 11 & -PD-FI & 44 & Male & No & No & No & No & No & $\begin{array}{l}\text { No implant failure or } \\
\text { peri-implantitis }\end{array}$ \\
\hline
\end{tabular}

The only reason why more patients were not included in the study was because the inclusion and exclusion criteria were strict and many of them were outside the designed sample. In the first instance, it was intended to include one more study group, Down S-syndrome patients w without periodontal disease but with failed implants. However, no patients with these characteristics were found. This could also be considered a result.

Demographic and clinical variables are taken from patients' medical records.

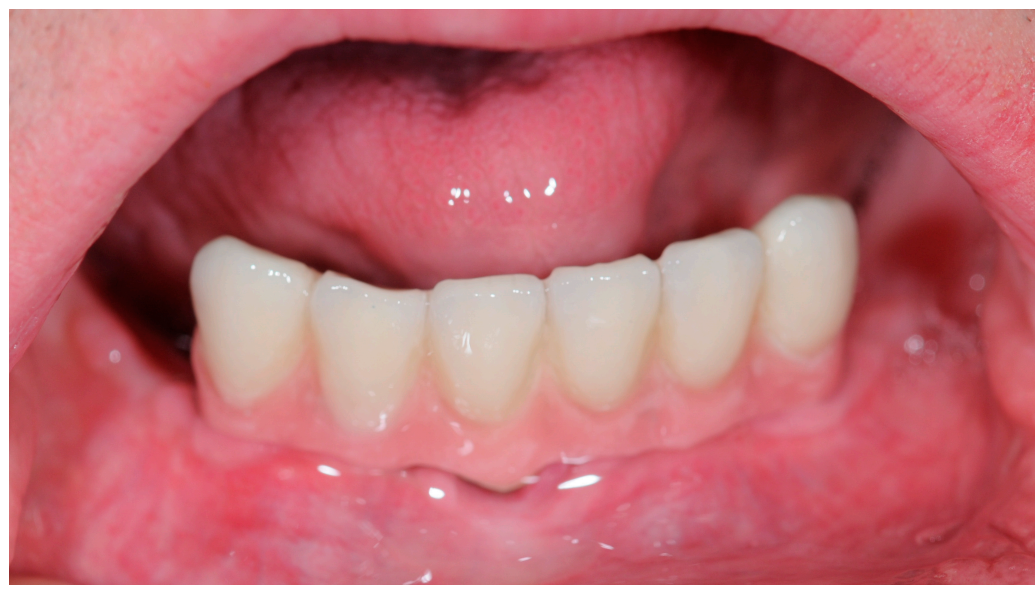

(a)

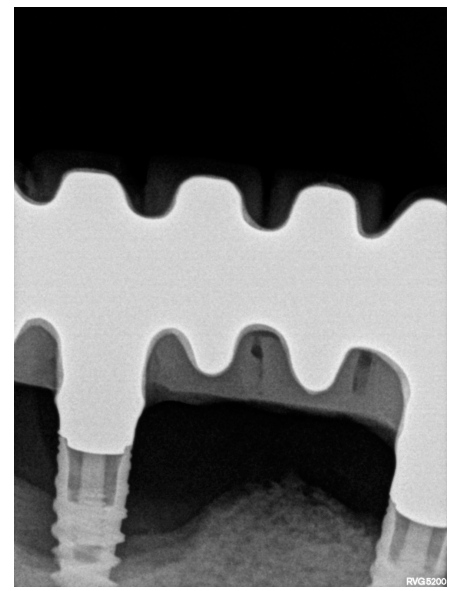

(b)

Figure 3. Patient 2 (+PD+FI). (a) Clinical view. (b) Radiographical view. After the loss of all teeth due to severe periodontitis, four implants were placed, two of which are affected by peri-implantitis with severe bone loss at the end of the follow-up. 


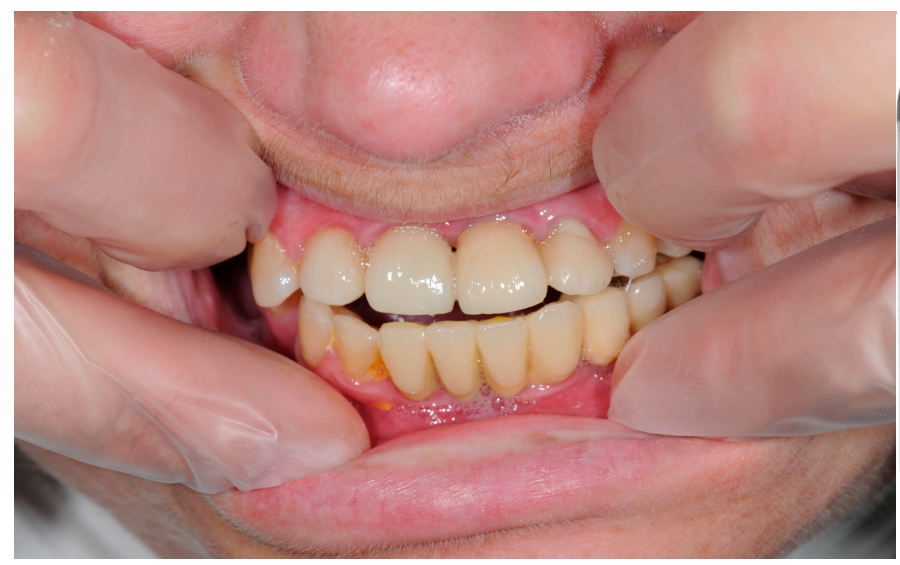

(a)

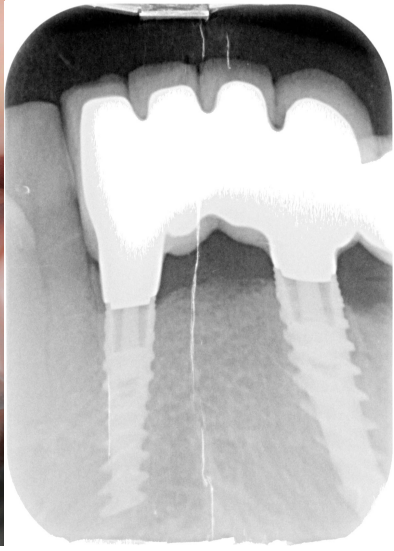

(b)

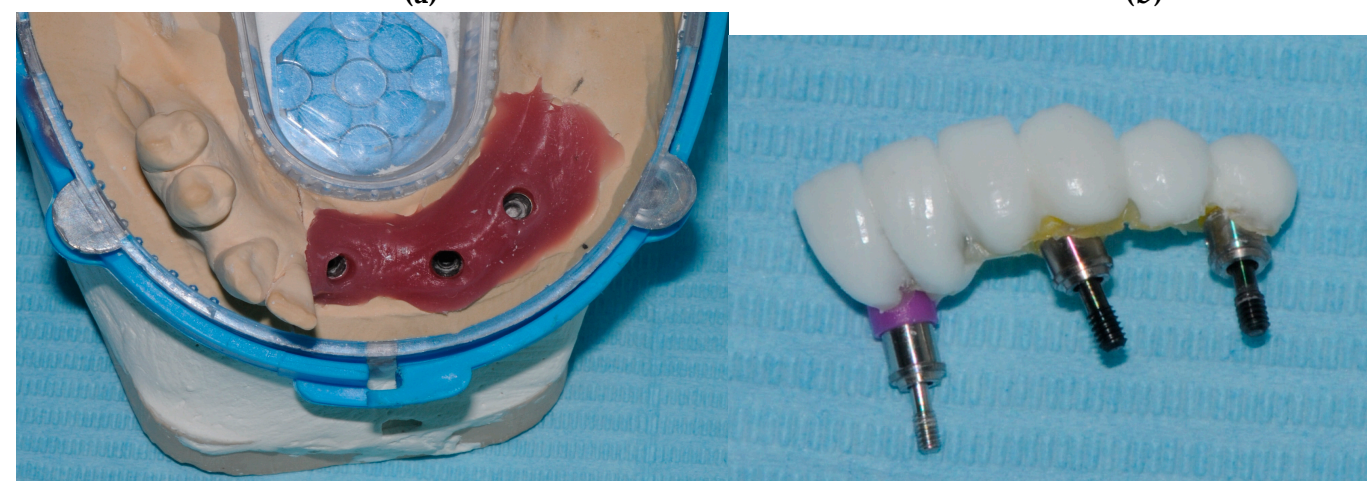

(c)

(d)

Figure 4. Patient 7 (-PD-FI). (a) Clinical view. (b) Radiographical view. (c) Prosthetic work model. (d) Dental prosthesis before being placed. The three implants were still in good shape two years after their placement.

\subsection{RNA Analysis}

The results obtained via RNA analysis using the Affymetrix Microarrays program, of the blood samples collected during the examination process, for the metallothioneins in the patients tested are shown in Table 2.

Table 2. Results table, with significant values, using Transcriptome Analysis Console Software 4.0 (ThermoFisher Scientific, Waltham, MA, USA) and 4.0.1.

\begin{tabular}{|c|c|c|c|c|c|c|c|}
\hline ID & $\begin{array}{c}+\mathrm{PD}+\mathrm{FI} \\
\text { (Average, } \log 2 \text { ) }\end{array}$ & $\begin{array}{c}\text {-PD-FI (Average, } \\
\log 2)\end{array}$ & $\begin{array}{c}\text { Fold } \\
\text { Change }\end{array}$ & $p$ Value & $\begin{array}{l}\text { Fdr } p \\
\text { Value }\end{array}$ & $\begin{array}{l}\text { Genetic } \\
\text { Symbol }\end{array}$ & Description \\
\hline TC1600007959 & 8.05 & 9.49 & -2.71 & 0.0014 & 0.9997 & MT1E & Metallothionein 1E \\
\hline TC1600007966 & 6.8 & 8.06 & -2.39 & 0.0018 & 0.9997 & MT1H & Metallothionein $1 \mathrm{H}$ \\
\hline TC1600011399 & 10.73 & 12.36 & -3.09 & 0.0021 & 0.9997 & MT1X & Metallothionein $1 \mathrm{X}$ \\
\hline TC1600007962 & 12.17 & 13.67 & -2.82 & 0.0023 & 0.9997 & MT1A & Metallothionein 1A \\
\hline TC1600007964 & 11.7 & 13.38 & -2.95 & 0.0024 & 0.9997 & $\begin{array}{l}\text { MT1B; } \\
\text { MT1C }\end{array}$ & $\begin{array}{l}\text { Metallothionein 1B; } \\
\text { Metallothionein 1C, } \\
\text { pseudogene }\end{array}$ \\
\hline TC1600007958 & 11.58 & 12.93 & -2.55 & 0.0048 & 0.9997 & MT1L & $\begin{array}{l}\text { Metallothionein 1L } \\
\text { (gene/pseudogene) }\end{array}$ \\
\hline TC1600007957 & 13.82 & 15.05 & -2.35 & 0.0072 & 0.9997 & MT2A & Metallothionein 2A \\
\hline TC1600007960 & 9.03 & 10.39 & -2.37 & 0.0092 & 0.9997 & MT1M & Metallothionein $1 \mathrm{M}$ \\
\hline TC1600010421 & 10.62 & 11.79 & -2.24 & 0.0118 & 0.9997 & MT1G & Metallothionein $1 \mathrm{G}$ \\
\hline
\end{tabular}

Filter values of $p$-value have been correctly established as 0.05/Filter values of Fold Change have been established between 2 and -2 ./The SW TAC will use the correct version of $\mathrm{R}$ for the analysis/Fdr $=$ False discovery rate.

The ones obtained via RNA analysis using the Affymetrix Microarrays program appear to show a low gene expression for metallothioneins, with a statistically significant value $(p<0.05)$.

The low gene expression of MTs, in particular, of isoforms of MT1E (Fold change (FD) -2.71 ; $p=0.0014), \mathrm{MT1H}(\mathrm{FD}-2.39 ; p=0.0018), \operatorname{MT} 1 \mathrm{X}(\mathrm{FD}-3.09 ; p=0.0021), \operatorname{MT} 1 \mathrm{~A}(\mathrm{FD}-2.82 ; p=0.0023)$, 
MT1B and C (FD -2.95; $p=0.0024)$, MT1L (FD) -2.35; $p=0.0048)$, MT2A (FD) -2.35; $p=0.0072)$, MT1M (FD -2.37; $p=0.0092)$, MT1G (FD -2.24; $p=0.0118)$, may be an indicator that the metallothionein pathway is altered in certain patients who suffer from Down syndrome with periodontal disease and peri-implant failure, compared to Down syndrome patients without periodontal disease and without peri-implant failure.

In our study results, genes corresponding to metallothioneins that are downregulated are only mainly MT1 and MT2A isoforms. However, for MT3 and MT4 no altered gene expression was found (Figure 5).

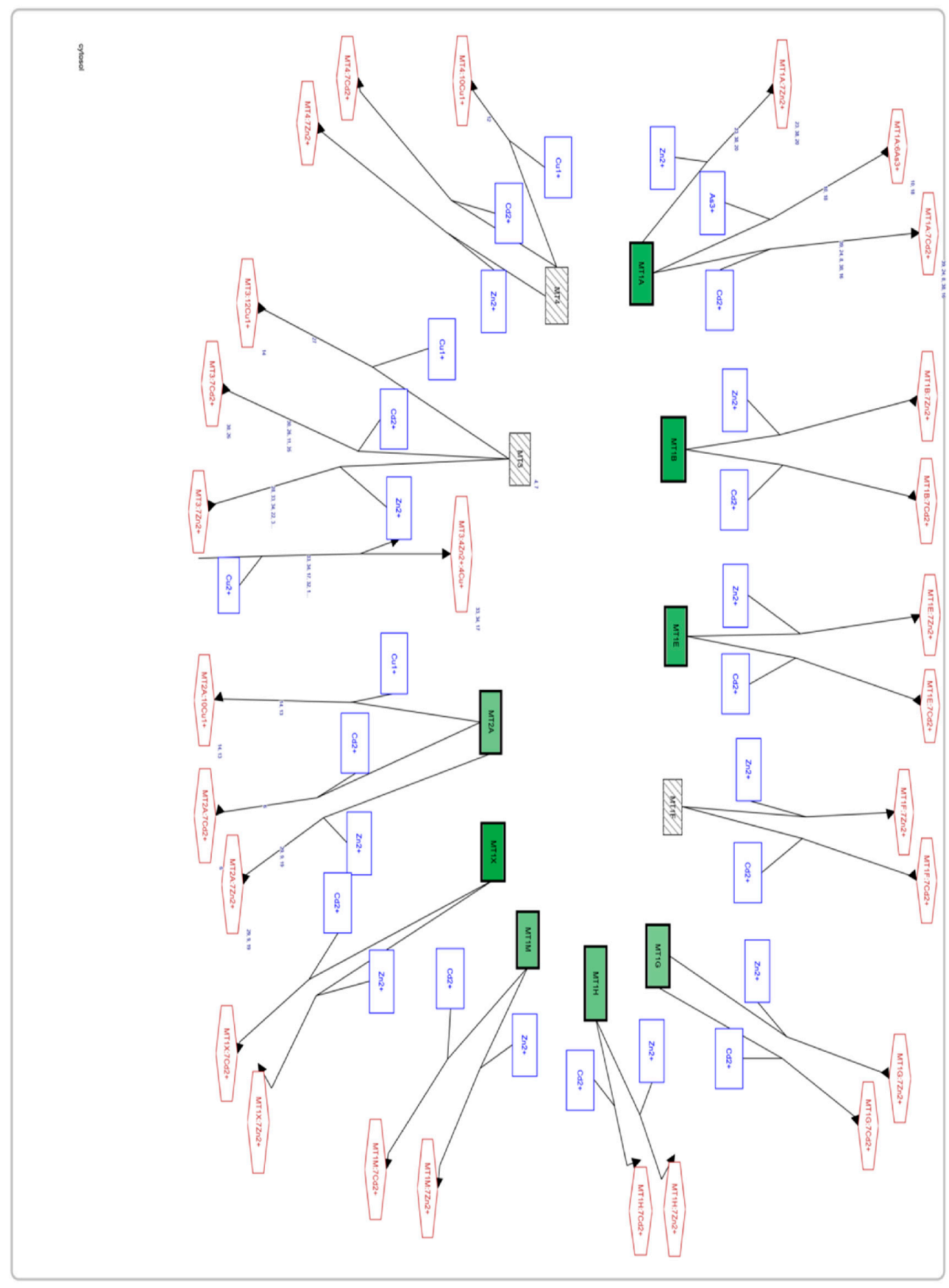

Figure 5. Screenshot of the Affymetrix Microarrays program on the metabolic pathway of the metallothioneins. Differences in genetic expression between the study groups are indicated, using the -PD-FI group as a control. Those genes that are downregulated are shown in green, upregulated genes (none are to be seen in the image) are in red, and genes with unaltered expression are in striped gray). 


\section{Discussion}

The results of the study confirm the alternative hypothesis, that metallothioneins are expressed inconsistently. The metallothioneins are downregulated in Down syndrome patients with periodontal disease and failed implants.

The clinical question that forms the basis of the investigation is whether it is possible to identify any alteration of genetic expression that is responsible for the appearance of periodontitis and loss of dental implants in patients with Down syndrome. In this sense, the focus of our research is when both situations occur together (not mixed; it is a unique clinical situation when both circumstances occur), because it really is a problematic clinical situation. If there is no periodontitis, there will probably be no dental loss in this type of patient. If there is no rejection, implant therapy is valid. That is, the clinical problem appears when both circumstances occur, so it is the focus of the study.

Studying both situations separately would be interesting, to identify the factors involved in each of these situations. This could be a research project for a later time since it presents some difficulties in its realization: from the outset, two more groups would be necessary: one of patients with Down syndrome, with implant failure, and without periodontal disease. This group, at least in our clinical experience, does not exist (which means that it will be very scarce). A second necessary group is patients with Down syndrome, without periodontal disease and without implant rejection. Although we have identified a small number of patients who would fit into this group, their number and condition do not make their inclusion in this study viable for the moment.

On the other hand, and despite not knowing in detail all the activities that metallothioneins can perform, using the published bibliography about them, together with the results obtained, we can reach an important hypothesis about the involvement of MTs both in osseointegration of implants in Down syndrome patients and in the onset of periodontal disease in these patients.

Oxidative stress has been related to the inhibition of osteoblast cell differentiation. A study by Liu et al. [16] shows that hydrogen peroxide $\left(\mathrm{H}_{2} \mathrm{O}_{2}\right)$ inhibits alkaline phosphatase activity in bone marrow stromal cells (BMSCs), among other early markers of bone-forming cell differentiation. To confirm the involvement of metallothioneins in this process, a culture of cells was attempted with prior MT treatment; it was observed that these protected the cells from inhibition by reactive oxygen species.

This study not only highlights the important role of metallothioneins as powerful antioxidant agents, which was already supported by numerous in vitro studies [17], but also how these have considerable significance when cell differentiation takes place in new bone formation.

The line of research from a previous study [16] continues to explore changes in expression in the different isoforms of MT in osteoporotic males and postmenopausal women. However, the researchers do not specify which metallothioneins were administered in the study cultures.

In this respect, in another study [18] where an assessment is made of whether metallothioneins play an important role in osteoblast differentiation and their level of expression in this process, the focus is only on MT1, MT2, and MT3 isoforms, also assessing the RNAm levels in alkaline phosphatase and osteocalcin to take them as reference points. In their results, no MT3 RNAm was detected at any time; with regard to MT1 and MT2, the RNAm levels rose significantly in the first $24 \mathrm{~h}$ in a culture treated with dexamethasone (Dex). This would show that MT1 and MT2 could develop a decisive role during the first stages of mesenchymal stromal stem cells (MSC) into osteoprogenitor bone cells. In fact, on adding an antisense oligonucleotide (a nucleotide chain with a sequence of bases complementary to a fragment of RNAm that would prevent its transcription) for MTs, it was observed that osteoblast differentiation and mineralization were considerably suppressed.

The fact that the expression of MT1 and MT2 genes seems to have important action during the first stages of bone-forming cell differentiation is an interesting starting point that strengthens the hypothesis put forward about the possible causes of failure of implants, and the lack of osseointegration, in Down syndrome patients. We cannot rule out that the condition evidenced by our study is related to the other pathological condition that differentiates both groups-that is, the onset of periodontal disease. 
It is important to highlight that a low gene expression of MT1 and MT2 in Down syndrome patients in our study has been observed when comparing patients with periodontal disease and failed implant treatment with patients who do not suffer from periodontal disease and have a positive experience of implant treatment, but we do not know what expression metallothionein genes would have if another study group with different characteristics of periodontal disease and implant evolution were used.

Alterations in the expression of the MT1 and MT2 genes can lead to clinical alterations in patients with Down syndrome, such as severe periodontal disease, implant loss, or peri-implantitis; they may be related to the aforementioned role of these molecules in the early stages of bone healing, which can lead to a failure of osseointegration or to the presence of a bone with little strength to withstand the aggressions of the oral environment- this being especially important in the case of both periodontitis and peri-implantitis. This points to a possible line of research that could put the data provided in this study into perspective.

Conversely, we should not forget that these results need to be studied in greater depth, starting with the validation of the gene expression identified in this study, using a complementary technique, which would confirm the initial results. Subsequently, the study should focus on genes with confirmed altered expression. On the other hand, more efforts should also be made to increase the number of patients and obtain larger samples in each group, as well as complementary groups, so that the analyses can gain solidity.

\section{Conclusions}

With the limitations of our study, the low MT1 and MT2 gene expression seems to be related to the onset of periodontal disease and implant rejection in Down syndrome patients, although more data are required to confirm whether this relationship is due to one of the two conditions, to both independently, or to the two jointly—-this last option being indicated by our current study.

Author Contributions: Conceptualization, R.G.-D., D.T.-L., G.M.-P., J.-L.G.-P. and M.-A.S.-F.; Formal analysis, M.B.-D. and R.G.-D.; Investigation, M.B.-D., R.G.-D., J.-R.C.-F., D.T.-L., J.-C.R.-V. and G.M.-P.; Methodology, M.B.-D., R.G.-D., J.-R.C.-F. and D.T.-L.; Project administration, D.T.-L. and J.-L.G.-P.; Supervision, J.-L.G.-P. and M.-A.S.-F.; Validation, J.-R.C.-F., D.T.-L. and M.-A.S.-F.; Writing一original draft, M.B.-D., R.G.-D., J.-R.C.-F., D.T.-L. and J.-C.R.-V.; Writing-review and editing, R.G.-D., J.-R.C.-F., J.-C.R.-V., G.M.-P., J.-L.G.-P. and M.-A.S.-F.

Funding: This study was funded by Consejería de Salud de la Junta de Andalucía (Spain) PI-0081-2016.

Conflicts of Interest: The authors declare no conflict of interest.

\section{References}

1. Hoffman, W., Jr.; Bomberg, T.J. Removable partial denture variations for the elderly patient. Gerodontics 1986, 2, 47-49. [PubMed]

2. Bhansali, S.; Tripathi, A.; Tiwari, S.C.; Singh, S.V. A study of the prosthodontic and oral health needs of an ageing psychiatric population. Gerodontology 2008, 25, 113-117. [CrossRef] [PubMed]

3. Visser, A.; de Baat, C.; Hoeksema, A.R.; Vissink, A. Oral implants in dependent elderly persons: Blessing or burden? Gerodontology 2011, 28, 76-80. [CrossRef] [PubMed]

4. Romero-Pérez, M.J.; Mang-de la Rosa, M.R.; López-Jimenez, J.; Fernández-Feijoo, J.; Cutando-Soriano, A. Implants in disabled patients: A review and update. Med. Oral Patol Oral Cir Bucal 2014, 19, e478-e482.

5. Corcuera-Flores, J.R.; López-Giménez, J.; López-Jiménez, J.; López-Giménez, A.; Silvestre-Rangil, J.; Machuca-Portillo, G. Four years survival and marginal bone loss of implants in patients with down syndrome and cerebral palsy. Clin. Oral Investig. 2017, 21, 1667-1674. [CrossRef] [PubMed]

6. Marín-Berná, M.; Velázquez-Cayón, R.T.; Torres-Lagares, D.; Hita-Iglesias, P.; Bouferrache, K.; Madrid, C.; Gutiérrez-Pérez, J.L. Failure in implant rehabilitation in a patient with severe congenital neutropenia (Kostmann syndrome). J. Oral Maxillofac. Surg. 2012, 70, e260-e263. [CrossRef] [PubMed]

7. Culebras-Atienza, E.; Silvestre, F.J.; Silvestre-Rangil, J. Possible association between obesity and periodontitis in patients with Down syndrome. Med. Oral Patol Oral Cir. Bucal. 2018, 23, e335-e343. [CrossRef] [PubMed] 
8. Ballesta-Mudarra, S.; Machuca-Portillo, G.; Torres-Lagares, D.; Rodríguez-Caballero, A.; Yáñez-Vico, R.M.; Solano-Reina, E.; Perea-Pérez, E. Determination of periodontopathogens in patients with Cri du chat síndrome. Med. Oral Patol. Oral Cir. Bucal. 2013, 18, e883-e887. [CrossRef] [PubMed]

9. Corcuera-Flores, J.R.; Castellanos-Cosano, L.; Torres-Lagares, D.; Serrera-Figallo, M.A.; Rodríguez-Caballero, A.; Machuca-Portillo, G. A systematic review of the oral and craniofacial manifestations of cri du chat syndrome. Clin. Anat. 2016, 29, 555-560. [CrossRef] [PubMed]

10. Maroni, G.; Wise, J.; Young, J.E.; Otto, E. Metallothionein gene duplications and metal tolerance in natural populations of drosophila melanogaster. Genetics 1987, 117, 739-744. [PubMed]

11. Egli, D.; Domènech, J.; Selvaraj, A.; Balamurugan, K.; Hua, H.; Capdevila, M.; Georgiev, O.; Schaffner, W.; Atrian, $\mathrm{S}$. The four members of the drosophila metallothionein family exhibit distinct yet overlapping roles in heavy metal homeostasis and detoxification. Genes Cells 2006, 11, 647-658. [CrossRef] [PubMed]

12. Moleirinho, A.; Carneiro, J.; Matthiesen, R.; Silva, R.M.; Amorim, A.; Azevedo, L. Gains, losses and changes of function after gene duplication: Study of the metallothionein family. PLoS ONE 2011, 6, e18487. [CrossRef] [PubMed]

13. Vašák, M.; Meloni, G. Chemistry and biology of mammalian metallothioneins. J. Biol. Inorg. Chem. 2011, 16, 1067-1078. [CrossRef] [PubMed]

14. Lagervall, M.; Jansson, L.E. Treatment outcome in patients with peri-implantitis in a periodontal clinic: A retrospective study. J. Periodontol. 2013, 84, 1365-1373. [CrossRef] [PubMed]

15. Corcuera-Flores, J.R.; Alonso-Domínguez, A.M.; Serrera-Figallo, M.A.; Torres-Lagares, D.; Castellanos-Cosano, L.; Machuca-Portillo, G. Relationship between osteoporosis and marginal bone loss in osseointegrated implants: A 2-year retrospective study. J. Periodontol. 2016, 87, 14-20. [CrossRef] [PubMed]

16. Liu, A.L.; Zhang, Z.M.; Zhu, B.F.; Liao, Z.H.; Liu, Z. Metallothionein protects bone marrow stromal cells against hydrogen peroxide-induced inhibition of osteoblastic differentiation. Cell Biol Int. 2004, 28, 905-911. [CrossRef]

17. Ruttkay-Nedecky, B.; Nejdl, L.; Gumulec, J.; Zitka, O.; Masarik, M.; Eckschlager, T.; Stiborova, M.; Adam, V.; Kizek, R. The role of metallothionein in oxidative stress. Int. J. Mol. Sci. 2013, 14, 6044-6066. [CrossRef]

18. Dohi, Y.; Shimaoka, H.; Ikeuchi, M.; Ohgushi, H.; Yonemasu, K.; Minami, T. Role of metallothionein isoforms in bone formation processes in rat marrow mesenchymal stem cells in culture. Biol Trace Elem. Res. 2005, 104, 57-70. [CrossRef]

(C) 2019 by the authors. Licensee MDPI, Basel, Switzerland. This article is an open access article distributed under the terms and conditions of the Creative Commons Attribution (CC BY) license (http://creativecommons.org/licenses/by/4.0/). 